\title{
PENGELOMPOKKAN MATA KULIAH DI PROGRAM STUDI FISIKA FMIPA UNSRAT BERDASARKAN PROSES PEMBELAJARAN MENGGUNAKAN ANALISIS CLUSTER
}

\author{
Djoni Hatidja*1, Lidya I. Momuat ${ }^{2}$, Charles E. Mongi ${ }^{3}$ \\ 1,3 Program Studi Matematika, FMIPA Universitas Sam Ratulangi \\ ${ }^{2}$ Program Studi Kimia, FMIPA Universitas Sam Ratulangi \\ *Corresponding author: dhatidja@gmail.com
}

\begin{abstract}
ABSTRAK
Tujuan penelitian ini, yaitu mengelompokkan mata kuliah yang diajarkan oleh dosen di Program Studi (PS) Fisika FMIPA UNSRAT berdasarkan mutu pelayanan jasa yakni kehandalan, daya tanggap, keyakinan, empati, dan bukti langsung menggunakan analisis cluster. Penelitian dilakukan dengan wawancara pada mahasiswa di PS Fisika FMIPA UNSRAT. Penelitian dilakukan dengan survei menggunakan metode simple random sampling. Data tersebut berupa proses pembelajaran dari mata kuliah yang diajarkan di PS Fisika FMIPA UNSRAT pada Semester Genap 2017/2018. Hasil penelitian menunjukkan bahwa karakteristik proses pembelajaran, mata kuliah yang diajarkan pada semester genap 2017/2018 di PS Fisika FMIPA UNSRAT dikelompokkan menjadi 9 cluster. Mata kuliah yang melaksanakan proses pembelajaran dengan baik terdiri dari 21 mata kuliah, yaitu PKN, ISD, PG, PIF, TME, FB, MS, MEKB, PL, MPF, FZP, FN, ML, ADWIG, AL, MPF, PFM, FIS, GEO, GEL dan BING sedangkan mata kuliah yang tidak melaksanakan proses pembelajaran dengan baik, yaitu mata kuliah FM, FISMAT2, ED2 dan DDM.
\end{abstract}

Kata kunci: mutu pelayanan, analisis cluster, mahasiswa, Euclid, dendogram

\section{GROUPING OF SUBJECTS IN PHYSICS STUDY PROGRAM, FACULTY OF MATHEMATICS AND NATURAL SCIENCES SAM RATULANGI UNIVERSITY BASED ON THE LEARNING PROCESS USING CLUSTER ANALYSIS}

\begin{abstract}
The purpose of this study is to classify the subjects taught by lecturers in the Physics Study Program of Sam Ratulangi University based on service quality, namely reliability, responsiveness, confidence, empathy, and direct evidence using cluster analysis. The study was conducted by interviewing students in the Physics Study Program Sam Ratulangi University using simple random sampling method. The data is in the form of a learning process from courses taught at the Physics Study Program Sam Ratulangi University in the Even Semester 2017/2018. The results showed that the characteristics of the learning process, courses taught in even semester 2017/2018 in Physics Study Program FMIPA UNSRAT were grouped into 9 clusters. The courses that carry out the learning process well consist of 21 subjects, i.e. PKN, ISD, PG, PIF, TME, FB, MS, MEKB, PL, MPF, FZP, FN, ML, ADWIG, AL, MPF, PFM, FIS , GEO, GEL and BING, while the courses don't carry out the learning process well, i.e. FM, FISMAT2, ED2 and DDM courses.
\end{abstract}

Keywords: service quality, cluster analysis, students, euclidean, dendogram

\section{PENDAHULUAN}

\section{Latar Belakang}

Salah satu lembaga pelayanan yang bergerak dalam jasa pendidikan adalah perguruan tinggi. Di perguruan tinggi, tenaga pendidik yakni dosen merupakan salah satu bagian dari pengolah jasa pendidikan yang memiliki karakteristik tertentu secara langsung maupun tidak langsung yang dijadikan dasar penilaian oleh mahasiswa khususnya dari segi kinerja. Dengan demikian, pengembangan produk jasa pendidikan dapat dilakukan melalui riset perilaku konsumen jasa pendidikan dan 
produk jasa pendidikan yang diberikan. Melalui riset ini dapat diperoleh informasi tentang kualitas karakteristik dari suatu produk jasa pendidikan di mata mahasiswa.

Perguruan tinggi merupakan lembaga pelayanan jasa pendidikan. Pelayanan adalah kunci keberhasilan dalam berbagai usaha atau kegiatan yang bersifat jasa (Moenir, 2008). Pengukuran kualitas pelayanan dalam hal ini pelayanan pendidikan merupakan elemen penting dalam menyediakan pelayanan yang lebih baik, lebih efisien dan lebih efektif.

Fakultas Matematika dan Ilmu Pengetahuan Alam Universitas Sam Ratulangi (FMIPA UNSRAT) merupakan lembaga pendidikan yang dapat dikatakan sebuah layanan jasa bidang pendidikan. Dalam pemberian jasa pendidikan FMIPA dituntut tidak hanya memberikan jasa dalam bentuk fisik tetapi juga memberikan pelayanan yang lebih profesional sehingga tercapai kualitas pelayanan yang baik yaitu kualitas pelayanan pendidikan yang didukung oleh tenaga pengajar yang kompeten dalam bidangnya.

Salah satu yang menjadi indikator pelayanan dosen terhadap mahasiswa di suatu Jurusan atau Program studi adalah nilai Akreditasi dari Program Studi. Beberapa butir yang dinilai dalam Akreditasi Program Studi adalah layanan kepada mahasiswa, pelaksanaan proses pembelajaran, perbaikan proses pembelajaran serta monitoring dan evaluasi kinerja akademik dosen (tenaga pendidik) dan tenaga kependidikan.

Tumilaar, Hatidja dan Prang (2014); Pangemanan, Hatidja dan Komalig (2014), Liputo, Hatidja dan Langi (2014), telah melaksanakan penelitian mengenai karakteristik kinerja dosen Program Studi Matematika dalam proses pembelajaran serta persepsi alumni Program Studi Matematika terhadap kurikulum dan proses pembelajaran. Penelitian ini dilaksanakan pada semester genap 2012/2013. Program studi Fisika merupakan bagian dari FMIPA UNSRAT juga perlu melakukan evaluasi proses pembelajaran untuk mengetahui kualitas pelayanan dari dosen.

Mengingat proses pembelajaran perlu dilakukan secara berkesinambngan serta secara menyeluruh, maka perlu dilakukan penelitian tentang kualitas pelayanan dari segi kinerja dosen pada proses pembelajaran dan layanan akademik lainnya di Program
Studi Fisika FMIPA UNSRAT pada semester Genap 2017/2018.

Analisis cluster merupakan salah satu bagian dari analisis peubah ganda yang dapat mengelompokkan objek-objek (mata kuliah) berdasarkan kemiripan karakteristik mutu pelayanan.

Tujuan penelitian ini, yaitu mengelompokkan mata kuliah yang diajarkan oleh dosen di Program Studi Fisika FMIPA UNSRAT berdasarkan mutu pelayanan jasa yakni kehandalan, daya tanggap, keyakinan, empati, dan bukti langsung menggunakan analisis cluster.

\section{METODE PENELITIAN}

\section{Populasi dan Sampel}

Data yang digunakan dalam penelitian adalah data primer yakni data yang diperoleh langsung dari sumber penelitian dengan menggunakan kuesioner dengan skala rasio yang diberikan kepada mahasiswa di program studi Fisika yang mengikuti mata kuliah pada semester genap 2017/2018.

Penilaian terhadap kinerja dosen dalam proses perkuliahan dilakukan oleh mahaiswa PS Fisika melalui mata kuliah yang diajarkan oleh dosen. Jumlah mata kuliah yang diajarkan di PS Fisiska FMIPA pada semester Genap 2017/2018 sebanyak 31, namun mata kuliah Skripsi tidak disurvei karena tidak melaksanakan proses perkuliahan. Proses pengambilan data menggunakan metode Simple random sampling (penarikan contoh acak sederhana).

Adapun prosedur pengambilan data metode multistage random sampling dengan stratifikasi adalah sebagai berikut memilih secara acak 50\% jumlah mahasiswa yang mengontrak mata kuliah, untuk diwawancara sesuai dengan kuisioner. Setiap mata kuliah di PS Fisika diasuh oleh 1 atau 2 dosen/tenaga pendidik. Oleh karena itu, kuesioner yang disebarkan pada setiap matakuliah mencakup penilaian terhadap 2 dosen tersebut dengan membagi 2 jumlah peserta untuk masing-masing dosen/tenaga pendidik. Adapun kode mata kuliah dapat dilihat pada Tabel 1. 
Tabel 1. Matakuliah yang dilaksanakan di PS Fisika pada Semester Genap 2017/2018

\begin{tabular}{|c|c|c|}
\hline No. & KODE & NAMA MATA KULIAH \\
\hline 1 & PKN & Pendidikan Kewarganegaraan \\
\hline 2 & & Ilmu Sosial dasar \\
\hline 3 & ISD & Bahasa Inggris \\
\hline 4 & PL & Pengetahuan Lingkungan \\
\hline 5 & $\mathrm{AL}$ & Asistensi Laboratorium \\
\hline 6 & MPF & Metode Pengukuran Fisika \\
\hline 7 & PFM & Pengantar Fisika Matematika \\
\hline 8 & FIS & Fisika \\
\hline 9 & PIS & $\begin{array}{l}\text { Pengantar Instrumentasi } \\
\text { Fisika }\end{array}$ \\
\hline 10 & PG & Pengantar Geofisika \\
\hline 11 & DDM & Dasar-dasar Manajemen \\
\hline 12 & TER & Termodinamika \\
\hline 13 & GEO & Geostatistik \\
\hline 14 & ED2 & Elektronika Dasar II \\
\hline 15 & FM2 & Fisika Matematika II \\
\hline 16 & MEK2 & Mekanika II \\
\hline 17 & GEL & Gelombang \\
\hline 18 & PK & Pemrograman Komputer \\
\hline 19 & $\mathrm{BF}$ & Biofisika \\
\hline 20 & SM & Seismologi \\
\hline 21 & FM & Fisika Medis \\
\hline 22 & FZP & Fisika Zat Padat \\
\hline 23 & ML & Mesin Listrik \\
\hline 24 & ARN & Analisis Runtun Waktu \\
\hline 25 & FN & Fisika Nuklir \\
\hline 26 & TME & Teori Medan Elektromagnetik \\
\hline 27 & METPF & Metodologi Penelitian Fisika \\
\hline 28 & MS & Metode Seismik \\
\hline 29 & FB & Fisika Bahan \\
\hline 30 & MEKB & $\begin{array}{l}\text { Metode Elektromagnetik dan } \\
\text { Kemagnetan Batuan }\end{array}$ \\
\hline 31 & & Skripsi \\
\hline
\end{tabular}

\section{Objek dan Peubah Penelitian}

Objek penelitian adalah mahasiswa peserta mata kuliah pada semester genap 2017/2018 di PS Fisika FMIPA UNSRAT.

Peubah-peubah yang diamati adalah peubah penentu mutu pelayanan yang terdiri dari Kehandalan, Daya Tanggap, Jaminan, Empati, dan Bukti Langsung. Peubah-peubah yang diamati disajikan pada tabel 2-6.

Tabel 2. Peubah Kehandalan (kedisiplinan) (X1)

\begin{tabular}{|c|l|}
\hline Peubah & \multicolumn{1}{|c|}{ Definisi } \\
\hline $\mathrm{x} 1 \mathrm{a}$ & Kehadiran dosen \\
\hline $\mathrm{x} 1 \mathrm{~b}$ & Disiplin Waktu Datang \\
\hline $\mathrm{x} 1 \mathrm{c}$ & Disiplin Waktu Selesai \\
\hline $\mathrm{x} 1 \mathrm{~d}$ & Disiplin Waktu Datang Mahasiswa \\
\hline
\end{tabular}

Tabel 3. Peubah Daya Tanggap (X2)

\begin{tabular}{|c|l|}
\hline Peubah & \multicolumn{1}{|c|}{ Definisi } \\
\hline x2a & $\begin{array}{l}\text { Kesediaan Membantu Kesulitan } \\
\text { Pemahaman Mahasiswa }\end{array}$ \\
\hline x2b & $\begin{array}{l}\text { Pemberian Kesempatan Bertanya di } \\
\text { kelas }\end{array}$ \\
\hline $\mathrm{x} 2 \mathrm{c}$ & Memahami penjelasan dari dosen \\
\hline $\mathrm{x} 2 \mathrm{~d}$ & Pemberian Informasi Tentang Silabus \\
\hline $\mathrm{x} 2 \mathrm{e}$ & $\begin{array}{l}\text { Pemberian informasi tentang } \\
\text { Deskripsi Singkat Materi }\end{array}$ \\
\hline $\mathrm{x} 2 \mathrm{f}$ & $\begin{array}{l}\text { Pemberian informasi tentang Hak dan } \\
\text { Kewajiban Mahasiswa }\end{array}$ \\
\hline $\mathrm{x} 2 \mathrm{~g}$ & Pemberian tugas rumah \\
\hline $\mathrm{x} 2 \mathrm{~h}$ & Tugas membuat makalah/presentasi \\
\hline $\mathrm{x} 2 \mathrm{i}$ & Pemberian ujian mid \\
\hline $\mathrm{x} 2 \mathrm{j}$ & $\begin{array}{l}\text { Pemberian Soal Ujian Mencakup } \\
\text { Seluruh Materi }\end{array}$ \\
\hline
\end{tabular}

Tabel 4. Peubah Jaminan (Penguasaan materi) (X3)

\begin{tabular}{|l|l|}
\hline Peubah & \multicolumn{1}{c|}{ Definisi } \\
\hline x3a & $\begin{array}{l}\text { Pemberian teori disertai contoh } \\
\text { praktis }\end{array}$ \\
\hline x3b & $\begin{array}{l}\text { Tugas rumah yang diberi mampu } \\
\text { membantu pemahaman mahasiswa }\end{array}$ \\
\hline x3c & $\begin{array}{l}\text { Makalah membantu pemahaman } \\
\text { materi }\end{array}$ \\
\hline x3d & Penilaian hasil kuis secara objektif \\
\hline x3e & $\begin{array}{l}\text { Mengajar sesuai silabus dan jadwal } \\
\text { mingguan }\end{array}$ \\
\hline x3f & Mengajar sesuai keahlian \\
\hline
\end{tabular}

Tabel 5. Peubah Empati (X4)

\begin{tabular}{|l|l|}
\hline Peubah & \multicolumn{1}{c|}{ Definisi } \\
\hline $\mathrm{x} 4 \mathrm{a}$ & $\begin{array}{l}\text { Pemberian pujian bila memperoleh } \\
\text { nilai baik }\end{array}$ \\
\hline $\mathrm{x} 4 \mathrm{~b}$ & Ditegur bila melakukan kesalahan \\
\hline $\mathrm{x} 4 \mathrm{c}$ & $\begin{array}{l}\text { Diberi kesempatan memperbaiki } \\
\text { nilai/remedial }\end{array}$ \\
\hline
\end{tabular}

Tabel 6. Peubah Bukti Langsung (X5)

\begin{tabular}{|l|l|}
\hline Peubah & \multicolumn{1}{c|}{ Definisi } \\
\hline x5a & $\begin{array}{l}\text { Tugas rumah dinilai dan diberi } \\
\text { komentar }\end{array}$ \\
\hline x5b & Makalah/presentasi diberi komentar \\
\hline x5c & Pemanfaatan alat bantu ajar/LCD \\
\hline
\end{tabular}

\section{Analisis Data}

Metode analisis yang dilakukan dalam penelitian ini ada 2 tahap. Tahapan analisis yang dilakukan adalah sebagai berikut:

1. Data asal dianalisis dengan statistika deskriptif untuk mengetahui gambaran 
data secara umum menggunakan software Microsoft Excel.

2. Melakukan analisis cluster dengan langkah-langkah sebagai berikut:

a. Hitung matriks jarak antar objek dengan menggunakan jarak euclidian.

b. Cari jarak terdekat antar cluster, $\mathrm{D}=\min \left(\mathrm{d}_{\mathrm{ik}}\right)$

c. Gabungkan obyek-obyek yang sesuai, misalkan dilambangkan dengan cluster $\mathrm{U}$ dan custer $\mathrm{V}$ untuk mendapatkan cluster gabungan (UV)

d. Hitung jarak cluser UV dengan clustercluster lain dengan rumus:

$\mathrm{d}_{(\mathrm{UV}) \mathrm{W}}=\min \left\{\mathrm{d}_{\mathrm{UW}}, \mathrm{d}_{\mathrm{VW}}\right\}$, dimana $\mathrm{d}_{\mathrm{UV}}$ dan $\mathrm{d}_{\mathrm{Vw}}$ adalah jarak terdekat antara cluster $\mathrm{U}$ dengan $\mathrm{W}$ serta $\mathrm{V}$ dengan $\mathrm{W}$.

e. Langkah 3 dan 4 diulang sampai menyisahkan 1 cluster

\section{HASIL DAN PEMBAHASAN}

\section{Mutu Pelayanan}

Kotler (2000) mengungkapkan Lima faktor yang menentukan mutu pelayanan meliputi:

1. Tangible (bukti langsung) mencakup fasilitas fisik, perlengkapan, pegawai dan sarana komunikasi

2. Reliability (kehandalan) yaitu kemampuan memberikan pelayanan yang dijanjikan dengan segera, akurat, dan memuaskan

3. Responsiveness (daya tanggap) yaitu keinginan staf membantu para pelanggan dan memberikan layanan dengan tanggap

4. Assurance (jaminan) mencakup pengetahuan, kompetensi, kesopanan dan sifat dapat dipercaya yang dimiliki staf

5. Empathy (empati) meliputi kemudahan dalam menjalin relasi, komunikasi yang baik, perhatian pribadi, dan pemahaman aaatas kebutuhan individu para pelanggan.

\section{Analisis Cluster}

Mata kuliah (MK) yang ditawarkan pada semester genap 2017/2018 di PS Fisika FMIPA UNSRAT berjumlah 35 yang terdiri dari 5 MK umum dan 30 MK program studi. Namun dari 35 MK yang ditawarkan, hanya 31 mata kuliah yang dikontrak oleh mahasiswa PS Fisika. Dari 31 MK, hanya 30 MK yang disurvei. MK Skripsi tidak dilakukan wawancara, karena MK tersebut tidak melakukan proses pembelajaran di kelas.

Mata kuliah umum diajarkan oleh 6 dosen yang berasal dari luar PS Fisika, sedangkan mata kuliah dari PS Fisika diajarkan oleh 12 dosen dari PS Fisika.

Analisis cluster bertujuan untuk mengelompokkan objek-objek berdasarkan kemiripan karakteristik yang dimiliknya. Kemiripan karakteristik objek-objek dalam suatu cluster memiliki tingkat kemiripan yang tinggi, sedangkan kemiripan karakteristik antar objek pada suatu cluster lain memiliki tingkat kemiripan yang rendah. Kemiripan antar objek dapat diukur dengan menggunakan ukuran jarak. Terdapat beberapa jenis jarak kedekatan yang sering digunakan dalam analisis cluster, antara lain jarak Euclidean, jarak Mahalanobis, jarak City-block (Manhattan), dan lain-lain (Mattjik dan Sumertajaya, 2011).

Pada penelitian ini menggunakan jarak euclidean. Menurut Rencher (2002), jarak euclidean digunakan jika peubahpeubah yang diamati tidak berkorelasi.

Fungsi jarak antara dua buah vektor $\mathbf{x}=\left(x_{1}, x_{2}, \ldots, x_{p}\right)^{\prime}$ dan $\mathbf{y}=\left(y_{1}, y_{2}, \ldots, y_{p}\right)^{\prime}$ ,didefinisikan:

$$
\begin{aligned}
\mathbf{d}(\mathbf{x}, \mathbf{y}) & =\sqrt{(\boldsymbol{x}-\boldsymbol{y})^{\prime}(\boldsymbol{x}-\boldsymbol{y})} \\
& =\sqrt{\sum_{j=i}^{p}\left(x_{j}-y_{j}\right)^{2}}
\end{aligned}
$$

$\begin{array}{lll}\text { Data } & \text { yang diperoleh } \\ \text { dianalisis, } & \text { sehingga } & \text { diperoleh }\end{array}$ dendogram (gambar 2).

Gambar 2 memperlihatkan dendogram dari mata kuliah yang dilaksanakan pada semester genap 2017/2018 di Program Studi Fisika FMIPA UNSRAT. Jika dendogram dipotong pada tingkat kemiripan $74 \%$, maka proses pembelajaran di PS Fisika dapat dikelompokkan menjadi 9 cluster.

Cluster pertama terdiri dari 21 Mata kuliah yaitu mata kuliah PKN, ISD, PG, PIF, TME, FB, MS, MEKB, PL, MPF, FZP, FN, ML, ADWIG, AL, MPF, PFM, FIS, GEO, GEL dan BING. Cluster ini merupakan mata kuliah yang melaksanakan proses pembelajaran paling baik dengan nilai ratarata lebih dari 74. Bahkan mata kuliah PG memiliki nilai rata-rata skor pembelajaran sebesar 9,05. 


\section{Dendrogram with Single Linkage and Euclidean Distance}

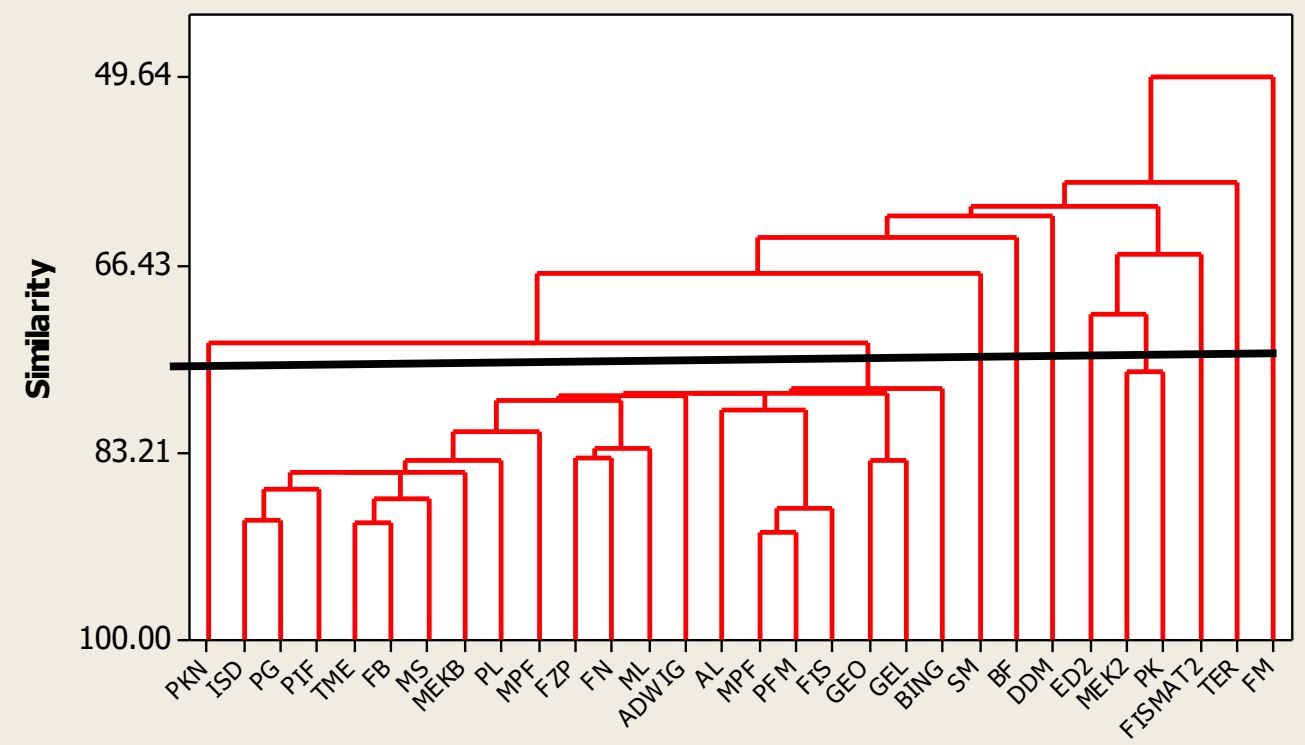

Mata Kuliah

Gambar 2. Dendogram Pengelompokkan Mata Kuliah di Program Studi Fisika FMIPA Universitas Sam Ratulangi

Cluster kedua terdiri dari mata kuliah SM; Cluster ketiga kedua terdiri dari mata kuliah BF; Cluster keempat kedua terdiri dari mata kuliah DDM; Cluster kelima terdiri dari mata kuliah ED2; Cluster keenam terdiri dari mata kuliah MEK2 dan PK; Cluster ketujuh terdiri dari mata kuliah FISMAT2; Cluster kedelapan terdiri dari mata kuliah TER; serta Cluster kesembilan kedua terdiri dari mata kuliah FM. Cluster kedua sampai kesembilan memiliki nilai rata-rata proses pembelajaran kurang dari 7.

Beberapa mata kuliah mempunyai nilai rata-rata proses pembelajaran kurang dari 6, yaitu mata kuliah FM $(4,86)$, FISMAT2 $(5,90)$, ED2 $(5,36)$ dan DDM $(5,18)$. Hal ini menunjukkan bahwa mata kuliah tersebut dalam proses pembelajarannya tidak memenuhi standar mutu yang telah ditetapkan. Rendahnya nilai rata-rata pada keempat mata kuliah tersebut karena: 1) dalam proses pembelajaran dosennya tidak menjelaskan silabus di awal perkuliahan, sehingga materi yang diajarkan tidak sesuai dengan silabus; 2) tidak melibatkan mahasiswa untuk membuat makalah yang akan dipresentasikan dan didiskusikan; serta 3) mahasiswa tidak diberikan kesempatan untuk memperbaiki nilai atau remedial.

\section{KESIMPULAN}

1. Berdasarkan karakteristik proses pembelajaran, mata kuliah yang diajarkan pada semester genap 2017/2018 di PS Fisika FMIPA UNSRAT dikelompokkan menjadi 9 cluster.

2. Mata kuliah yang melaksanakan proses pembelajaran dengan baik terdiri dari 21 mata kuliah, yaitu PKN, ISD, PG, PIF, TME, FB, MS, MEKB, PL, MPF, FZP, FN, ML, ADWIG, AL, MPF, PFM, FIS, GEO, GEL dan BING.

3. Mata kuliah yang tidak melaksanakan proses pembelajaran dengan baik, yaitu mata kuliah FM, FISMAT2, ED2 dan DDM.

\section{DAFTAR PUSTAKA}

Kotler, P. 2000. Marketing Management. Prentice hall,Inc. New Jersey.

Liputo, D., D. Hatidja dan Y.A.R. Langi. 2014. Analisis Korepondensi Terhadap Karakteristik Kinerja Dosen Berdasarkan Faktor Penentu Mutu Pelayanan Di Jurusan Matematika Fmipa Universitas Sam Ratulangi. Jurnal De Cartesian 3(1): 50-57. 
Mattjik, A.A. dan I.M. Sumertajaya. 2011. Sidik Peubah Ganda. Departemen Statistika FMIPA, IPB. Bogor.

Moenir, A. S. 2008. Manajemen Pelayanan Umum di Indonesia. Bumi Aksara. Jakarta

Pangemanan, Y., D. Hatidja dan H.A.H. Komalig. 2014. Persepsi Alumni Matematika Terhadap Layanan dan Fasilitas Akademik Serta Penelitian dan Pengabdian kepada Masyarakat Di Program Studi Matematika FMIPA UNSRAT dengan Menggu-nakan Analisis Korespondensi. Jurnal De Cartesian 3(1): 36-42.

Rencher, A.R. 2002. Methods of Multivariate Analysis Second Edition. John Wiley and Sons, Inc, New York.

Tumilaar, P., D. Hatidja dan J.D. Prang. Analisis Korespondensi Terhadap Persepsi Alumni Program Studi Matematika FMIPA Universitas Sam Ratulangi Mengenai Kurikulum Dan Proses Pembelajaran. Jurnal De Cartesian 3(1): 23-29. 